\title{
ROTINA FAMILIAR E ACADÊMICA DE FAMÍLIAS DE ALUNOS DURANTE O ISOLAMENTO SOCIAL
}

\author{
Laura Borges iD1 e Fabiana Cia iD 2
}

\section{Resumo}

A pandemia global do Coronavírus causou a interrupção das aulas presenciais, forçando escolas a se reorganizarem para continuar as atividades de forma remota. Assim, surgiu a necessidade de analisar as particularidades da realização deste processo na rotina das famílias dos alunos. O presente estudo tem como objetivo geral verificar o funcionamento da rotina familiar e acadêmica de crianças da Educação Infantil e dos Anos Iniciais do Ensino Fundamental de escolas públicas e particulares de uma cidade do interior paulista, a partir do relato dos familiares. 0 objetivo específico foi analisar o relacionamento e comunicação entre família e escola neste período, e o impacto das demandas escolares na rotina dos familiares. Para isso, após cumpridos os procedimentos éticos, a coleta de dados foi realizada a partir do envio de um formulário eletrônico, via e-mail, aos familiares de alunos da Educação Infantil e dos Anos Iniciais do Ensino Fundamental do município. Os dados qualitativos obtidos foram submetidos à análise de conteúdo, passando por operação de desmembramento em unidades de conteúdo e categorização. Os dados quantitativos foram submetidos a medidas de tendência central e dispersão. Foram identificados focos de alerta na retomada das aulas remotas, como sobrecarga materna, dificuldade em compartilhar das atividades da criança, insuficiência das orientações escolares, necessidade de aprimoramento da comunicação e nãovariedade das ferramentas utilizadas para tal. Estas constatações devem ser alvo de ação dos governantes, diretores e professores de modo a otimizar este processo educacional.

Palavras-chave: Relação família e escola; Ensino remoto; Pandemia; Covid-19; Coronavírus.

\section{FAMILY AND ACADEMIC ROUTINE OF STUDENTS FAMILIES DURING SOCIAL ISOLATION}

\section{Abstract}

The global Coronavirus pandemic caused disruption of face-to-face classes, forcing schools to take remote classes. Thus, the need arose to analyze the particularities of carrying out this process in the students 'families' routine. The present study has the general objective of verifying the functioning of the family and academic routine of children in kindergarten and elementary school I in public and private schools, of a city in the interior of São Paulo, based on the report of family members. The specific

${ }^{1}$ Pós-doutoranda no Programa de Pós-graduação em Educação Especial, Departamento de Psicologia, Universidade Federal de São Carlos.

${ }^{2}$ Professora Associada I do Departamento de Psicologia. Programa de Pós-graduação em Educação Especial, Universidade Federal de São Carlos.

Perspectivas em Diálogo, Naviraí, v. 8, n. 16, p. 202-217, jan./abr. 2021. 
objective was to analyze the relationship and communication between family and school in this period, and the impact of these school demands on the family's routine. For this, after fulfilling the ethical procedures, data collection was carried out by sending an electronic form, via e-mail, to the families of students in kindergarten and elementary school I in the municipality. The qualitative data obtained were subjected to content analysis, undergoing a breakdown operation into content and categorization units. Quantitative data were subjected to measures of central tendency and dispersion. Alert points were identified in the resumption of remote classes, such as maternal overload, difficulty in sharing the child's activities, insufficient school guidance, need to improve communication and the variety of tools used to do so. These findings must be the focus of action by government officials, directors and teachers in order to optimize this educational process.

Keywords: Family and school relationship; Remote teaching; Pandemic; Covid-19; Coronavirus.

\section{Introdução}

Nos últimos meses, o mundo tem passado por um novo contexto social em decorrência da pandemia do novo Coronavírus, o qual foi registrado pela primeira vez na China, no ano de 2019, e se espalhou por praticamente todo o mundo (ORGANIZAÇÃ̃O MUNDIAL DA SAÚDE, 2020).

O vírus (2019-nCoV) pertence à grande família viral dos coronavírus, o qual se instala no sistema respiratório causando infecções com sintomas semelhantes a uma gripe ou resfriado (CONSELHO REGIONAL DE FARMÁCIA, 2020). Entretanto, outra importante característica do vírus é sua velocidade e facilidade de disseminação e contágio. Sendo assim, de acordo com a Sociedade Brasileira de Infectologia (SBI) (2020), ambientes fechados e com grande número de pessoas são extremamente susceptíveis à contaminação. Além disso, este vírus apresenta risco gravíssimo a certos grupos de pessoas, como idosos e pessoas com doenças cardiorrespiratórias, crônicas e autoimunes (SBI, 2020).

A facilidade e velocidade do contágio fazem com que muitas pessoas se contaminem ao mesmo tempo, ocasionando a superlotação dos serviços de saúde, os quais, por sua vez, não estavam (e muitos ainda não estão) preparados para receber esta demanda brusca e elevada. Por este motivo, as mortes em muitos países alcançaram números extremamente elevados de forma muito rápida, colocando o mundo em uma situação pandêmica, necessitando que medidas emergenciais e radicais fossem tomadas (SBI, 2020).

Umas das primeiras ações de forma a minimizar a velocidade de contágio e evitar a sobrecarga dos sistemas de saúde foram a mudança nos hábitos de higienização e o distanciamento social (BRASIL, 2020). Até este momento, as orientações envolviam cautela e busca por evitar contatos físicos, como cumprimentos, abraços e apertos de mão, além da manutenção de uma distância física segura entre as pessoas. Sendo estas recomendações reforçadas para os casos de ambientes que comportavam um grande número de sujeitos, como escolas.

Sobre as instituições educacionais, no início de março, a SBI manifestou-se: 
Neste momento da epidemia no Brasil não está recomendado fechar escolas ou faculdades ou escritórios. O fechamento de escolas pode levar a várias famílias a terem que deixar seus filhos com seus avós, pois seus pais trabalham. Nas crianças, a COVID-19 tem se apresentado de forma leve e a letalidade é próximo a zero; já no idoso, a letalidade aumenta muito. No idoso com mais de 80 anos e comorbidades, a letalidade é em torno de $15 \%$. Portanto o fechamento de escolas em cidades em que os casos são importados ou a transmissão é local (ver definições no fim deste informe) pode ser prejudicial para sociedade! Esta orientação é dinâmica, podendo ser modificada, conforme a evolução da epidemia, particularmente nas cidades e estados em que a epidemia evoluir para transmissão comunitária (SBI, 2020, p. 2).

De fato, como pontuado, tais orientações necessitaram de reformulação devido ao aumento do contágio em território nacional, em meados de março. Assim, recomendou-se que, a fim de garantir um distanciamento social realmente seguro, atividades e serviços que envolvessem aglomerações deveriam ser interrompidos, como shows, eventos, cultos religiosos, presença de torcidas em jogos esportivos e, sobretudo, as atividades escolares presenciais.

O Governo do estado de São Paulo decretou, portanto, a suspensão gradual das aulas das escolas estaduais, municipais e particulares, como medida preventiva não-farmacológica de diminuir a circulação de pessoas, com vistas a evitar o aumento da transmissão viral, uma vez que "crianças e jovens em muitos casos não apresentam sintomas, mas podem ser transmissores do vírus, pondo em risco as próprias famílias e os servidores da escola, especialmente os idosos" (SÃO PAULO, 2020a).

Embora as atividades escolares sejam um serviço extremamente importante e essencial à sociedade, possui características que favorecem a contaminação em grande escala, como o fato de abrigar um número considerável de alunos em um local fechado por várias horas, e pela grande circulação e fluxo de pessoas diferentes ao longo do dia, visto que muitas escolas funcionam em até três períodos. Deste modo, encerradas as aulas presenciais no dia 20 de março, foi recomendada a continuidade das atividades à distância, sem previsão de retomada das aulas presenciais.

O Comunicado da Coordenadoria Pedagógica do Estado de São Paulo (COPED), de 17 de março de 2020 (SÃO PAULO, 2020b), propõe algumas sugestões de atividades a serem realizadas durante o isolamento, como projetos interdisciplinares, listas de exercícios, leitura e produção de textos e projetos de iniciação científica, com orientações de acordo com o segmento ou componente curricular. Considerando o Atendimento Educacional Especializado (AEE), oferecido aos alunos do Público Alvo da Educação Especial (PAEE), seja este itinerante ou em Classe Regida por Professor Especializado-CRPE, orientou-se que:

[...] os professores elaborem roteiros de estudos enriquecedores dos conteúdos desenvolvidos até o momento, para consolidação e aprofundamento do que já foi trabalhado. Caberá à equipe gestora, juntamente com os professores especializados, orientar os pais/responsáveis em relação ao roteiro de estudos e sobre a importância da estimulação do estudante durante o período de suspensão necessária e importante das aulas. Tais orientações também se estendem às instituições credenciadas com a Pasta, por meio de contrato ou Termo de Colaboração, que atendem a alunos Público Alvo da Educação Especial (SÃO PAULO, 2020b, p. 9). 
Tendo a velocidade de contaminação elevada a cada dia, outras medidas precisaram ser tomadas, como o decreto de quarentena e o isolamento social, com a orientação de que a população ficasse em suas residências, evitando contato com outras pessoas, assim como o fechamento de vários outros serviços não essenciais, como restaurantes, lanchonetes, comércios, escritórios, dentre outros (SÃO PAULO, 2020c).

Essa ação modificou a rotina e a dinâmica da vida de grande parte da população brasileira, que ainda se encontra tentando se adequar à esta situação inusitada. Muitas famílias passaram por mudanças na área laboral, realizando a totalidade ou parte do trabalho de sua casa, tendo a carga de horas reduzida, ou até mesmo, acabaram perdendo o emprego. As crianças, por sua vez, impossibilitadas de frequentar a escola, passaram a ficar sob única e exclusiva responsabilidade dos familiares, em casa. Desta forma, as reorganizações familiares neste período têm sido constantes, na tentativa de manejar e lidar com as demandas do trabalho, da vida pessoal, econômica e parental.

Diante do cenário de isolamento social, muitas instituições de ensino interromperam por completo suas atividades, pois não se tinha conhecimento e informação sobre a duração deste período. Outros contextos, como as Instituições de Ensino Superior (IEs) particulares, buscaram maneiras de continuar oferecendo o serviço educacional, utilizado como estratégia o ensino remoto ou à distância, como sugerido pelo Ministério da Saúde (BRASIL, 2020).

Uma das questões cruciais referente à educação durante o isolamento social, causado pela pandemia do Coronavírus, foi a demora na orientação e divulgação de diretrizes específicas, tanto em âmbito nacional, quanto estadual e municipal, às escolas, principalmente as de ensino básico e público.

O que se verifica atualmente são unidades agindo por decisão própria, sem diretriz legal e sem acompanhamento, amparo, orientação, ou planejamento estratégico. Enquanto havia escolas com aulas interrompidas, algumas decretaram férias e outras deram continuidade ao calendário acadêmico, improvisando os métodos de ensino das mais variadas formas, como vídeo aulas, ensino remoto, envio de atividades e materiais às famílias, dentre outros.

Essa ausência de diretriz e de regulamentação pode vir a ter resultados negativos na educação nacional, principalmente no que se refere à qualidade de serviço e na equiparação do acesso ao ensino pelas diferentes classes sociais, o que por si só já aumenta a desigualdade social, além de acarretar em diversos outros problemas para o país.

Em meados de maio, devido ao fato de não haver previsão de retorno das atividades escolares presenciais no Estado de São Paulo, após transcorridos mais de dois meses de interrupção das aulas presenciais, iniciou-se um movimento de retomada das atividades acadêmicas à distância/remotas por parte das escolas que se encontravam, até então, com as aulas suspensas.

A maneira como isso vai ocorrer ainda é desconhecida e, possivelmente, virá a passar por constantes readequações, conforme for sendo empregada. Também não é possível prever como e quais ferramentas serão utilizadas, assim como, mensurar a eficiência e a qualidade do ensino, a adesão e a capacidade de adaptação por parte das crianças e suas famílias.

Contudo, é preciso destacar alguns pontos que necessitam de atenção e avaliação no emprego deste novo formato de ensino nas escolas de educação básica, 
sobretudo, de Educação Infantil e Anos Iniciais do Ensino Fundamental, cujos alunos são mais dependentes de um adulto da família para realizar as atividades acadêmicas.

\section{Referencial teórico}

A primeira questão a se ponderar é o fato de unificar, pelo menos em âmbito municipal ou de unidade escolar, o método e a ferramenta de ensino. Ao propor o formato, os gestores municipais e das próprias escolas precisam considerar as especificidades existentes em cada contexto escolar, o qual é composto por crianças com características diferentes, as quais vêm de famílias e vivências também diversificadas. Esta heterogeneidade precisa ser considerada ao se propor e solicitar o envolvimento e participação dos pais nas atividades acadêmicas das crianças (LOPES, 2008; BOTELHO, 2015; SILVA; KAULFUSS, 2015; BORGES, 2018).

Sabe-se que um professor na sala de aula, mesmo tendo todos os alunos sob sua supervisão, oferendo os materiais e instruções necessários ao ensino, com o amparo de todos os recursos disponíveis, muitas vezes encontra dificuldade em atender às particularidades dos alunos e de seus contextos familiares. Como garantir esse atendimento em outras modalidades?

Assim, é preciso questionar se um modelo de ensino remoto ou à distância vai conseguir suprir a heterogeneidade, não só em relação aos alunos e suas características de aprendizagem, mas também do contexto familiar dessa criança, cujos membros serão requisitados a participar diretamente do processo de ensino; necessitando, desta forma, terem suas particularidades consideradas (OLIVEIRA; MARINHO-ARAUJO, 2010; RIBEIRO, 2012).

Deste bojo derivam outros pontos de atenção. As famílias, principalmente dos alunos das escolas públicas, possuem uma variação de classe social muito grande, englobando desde lares cujas condições socioeconômicas permitem fornecer ou adquirir equipamentos tecnológicos para que a criança realize as atividades, como computador, caixas de som, webcam, tablets ou smartphones, até famílias cujas crianças estão em situação de extrema vulnerabilidade social, necessitando de doações de itens para os cuidados básicos de higiene e alimentação. Nessa realidade nacional tão desigual, que se apresenta até mesmo dentro de uma única sala de aula, como oferecer uma modalidade de ensino durante o isolamento que atenda a todas as famílias e alunos?

Não obstante, outro foco de análise necessita ser a disponibilidade de tempo dos familiares para a participação nestas atividades, uma vez que mesmo no ensino convencional/presencial, o envolvimento destes nas atividades acadêmicas das crianças já é aquém do necessário (SILVA; CABRAL; MARTINS, 2016; BORGES, 2018).

Em meio a tantas mudanças, incertezas e imprevisibilidades, as famílias estão em constante reorganização, tentando ajustar suas rotinas e conciliar todas as demais demandas do dia a dia, como o cuidado com os filhos, com a casa e o trabalho. A falta de tempo, há muito, é uma das principais barreiras quando se trata da participação dos familiares na escolarização da criança (OLIVEIRA, 2010; REIS, 2013; BORGES, 2015; BORGES, 2018). Diante disso, como exigir participação e dedicação de pais que já possuem suas atividades programadas, ou que podem estar cumprindo os horários de trabalho de casa, ou que até mesmo estão procurando por 
um outro emprego devido às demissões em massa que ocorreram nos últimos tempos? Como solicitar a participação de um familiar membro cuja família é composta por somente um dos genitores (monoparental)? E quando esse único genitor possui mais de um filho em idade escolar?

E mesmo considerando um cenário próximo ao que se julga um "modelo ideal", cuja família possui recursos econômicos e pelo menos um familiar com disponibilidade de tempo para auxiliar essa criança, será que este teria conhecimento, habilidade, didática, sensibilidade e todas as demais exigências técnicas pedagógicas para fazer a mediação do ensino?

Também é preciso ressaltar as famílias cuja criança é do PAEE, ou que possui alguma necessidade ou atraso no desenvolvimento. Tais contextos, muitas vezes, já possuem uma rotina mais sobrecarregada devido aos atendimento, tratamentos, acompanhamentos e serviços que a criança normalmente frequenta (GUALDA; BORGES; CIA, 2013; SILVA; KAULFUSS, 2015). Além disso, não raro, um dos familiares acaba sendo mais afetado por essa sobrecarga - normalmente, a mãe (DESSEN; SILVA, 2001; OLIVEIRA, 2010; ALEXANDRE, 2012; BOTELHO, 2016 ). Pensando na retomada do ensino em outra modalidade que não a presencial, seriam essas crianças e a dinâmica de sua família consideradas? E as crianças PAEE que necessitam de materiais, atividades e/ou currículos adaptados?

Além de todos estes pontos, deve-se questionar também o provável impacto deste isolamento no relacionamento e comunicação entre a família e os profissionais escolares, uma vez que muitos pais utilizam os momentos de levar e buscar o filho na escola para trocarem informações com os professores e diretores (OLIVEIRA, 2010; BORGES, 2018). Como ficam a comunicação e parceria entre família e escola, tão necessárias e importantes para o desenvolvimento e aprendizagem das crianças?

Ainda que todas as famílias, de uma forma ou outra, consigam se adaptar a esta realidade, é preciso questionar se as condições de acesso e a eficiência do método seriam equiparadas entre alunos de escolas públicas e particulares, visto que muitas destas últimas não chegaram nem a interromper suas atividades, estabelecendo medidas de continuidade assim que decretado o isolamento.

Vê-se, portanto, que são inúmeras as questões a serem consideradas, ponderadas, analisadas e avaliadas durante a implementação desse plano de retomada. Neste sentido, julga-se necessário buscar compreender como vem ocorrendo este processo nas escolas públicas e particulares, principalmente de crianças da Educação Infantil e dos Anos Iniciais do Ensino Fundamental, com destaque às crianças do PAEE.

Deste modo, o objetivo geral desta pesquisa é verificar o funcionamento da rotina familiar e acadêmica de crianças da Educação Infantil e dos Anos Iniciais do Ensino Fundamental de escolas públicas e particulares, a partir do relato dos familiares. Como objetivo específico, buscou-se analisar o relacionamento e comunicação entre família e escola neste período, e o impacto destas das demandas escolares na rotina dos familiares.

\section{Metodologia}

A amostra foi composta por cinco familiares de crianças matriculadas na Educação Infantil e Anos Iniciais do Ensino Fundamental do interior paulista. A 
pesquisa foi aprovada pelo Comitê de Ética (CAEE: 33426920.0.0000.5504, $\mathrm{n}^{0}$ do Parecer: 4.133.401).

A amostra é composta por cinco mães entre 35 e 46 anos, cuja formação varia entre ensino médio incompleto e pós-graduação. Quanto à ocupação, tem-se: esteticista, diretora comercial, nutricionista, fisioterapeuta e dona de casa. Os filhos das participantes eram duas meninas e três meninos, com idade entre três e seis anos, sendo três matriculados na Educação Infantil particular, um na Educação Infantil pública e uma nos Anos Iniciais do Ensino Fundamental particular.

Três participantes têm a família composta por três pessoas e duas têm a família com quatro membros. Todas declararam haver pelo menos um membro da família em isolamento social no período.

Quanto aos procedimentos para coleta de dados, utilizou-se um formulário online sobre rotina e envolvimento familiar nas atividades acadêmicas da criança durante 0 isolamento, elaborado pelas autoras. Após autorização das escolas, o mesmo foi enviado por e-mail aos familiares, seguido de todas as instruções e orientações de preenchimento, assim como do Termo de Consentimento Livre e Esclarecido.

Os dados qualitativos passaram por operações de desmembramento em unidades de conteúdo e categorização (GIL, 1999). Os quantitativos passaram por medidas de tendência central e dispersão, seguindo os procedimentos propostos por Cozby (2006).

Importante ressalvar que, neste ínterim, se optou por analisar os dados a partir desta amostra pela necessidade de se obter um panorama inicial dos pontos a serem trabalhados com estes públicos, como medida de intervenção imediata, uma vez que a realização de uma coleta com uma amostra mais expandida e robusta demandaria mais tempo, impedindo a obtenção de subsídios norteadores de ações à curto prazo.

\section{Resultados e discussões}

Os resultados foram organizados em dois tópicos, tais como: Rotina e envolvimento familiar nas atividades acadêmicas da criança durante 0 isolamento social; e Relação das famílias com as demandas da rotina durante isolamento social.

\subsection{Rotina e envolvimento familiar nas atividades acadêmicas da criança durante $o$ isolamento social}

A partir da análise dos dados obtidos, destaca-se, primeiramente, que todos os participantes são do gênero feminino, ou seja, mães dos alunos. Esta constatação reafirma uma tendência já existente em pesquisas na área (DESSEN; SILVA, 2001; OLIVEIRA, 2010; GOITEIN; CIA, 2011; BORGES; GUALDA; CIA, 2015), na qual, quando se trata de assuntos relacionados à criança ou ao seu processo escolar, a responsável e a fonte de informação é, majoritariamente, a figura materna.

Além disso, quatro das cinco participantes estavam empregadas profissionalmente, ou seja, possuíam também a atividade laboral para gerenciar.

Quanto aos estudos acadêmicos, verificou-se que todas as crianças estavam realizando algum tipo de atividade escolar direcionada à distância, em sua residência, durante $o$ isolamento. 
Figura 1. Atividades escolares realizadas durante isolamento social

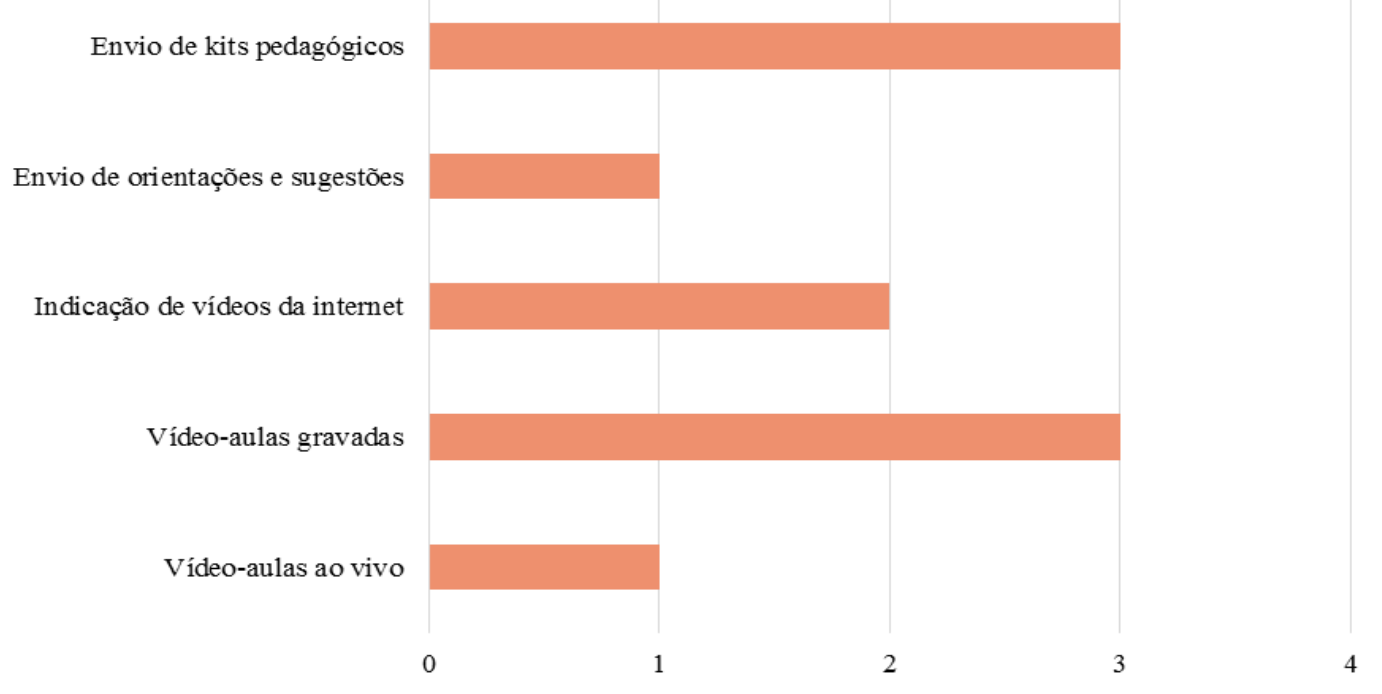

Fonte: Elaborado pelas autoras (2020).

As atividades realizadas pela maioria das famílias junto às crianças eram vídeoaulas gravadas e a utilização dos kits de estudo (apostilas, materiais de leitura, atividades, livros e materiais escolares, como canetinhas, massinha de modelar, tintas, etc.), disponibilizados pela escola.

Nesta proposta, as atividades são complementares, de modo que a família recebe o kit para que possa realizar, em casa, as atividades solicitadas pelos professores (em forma de instrução verbal/escrita, ou nas aulas gravadas pelos professores).

A Tabela 1 mostra a atribuição de nota dos familiares ( 0 a 10) à frequência de comunicação com o professor da criança.

Tabela 1. Nota atribuída pelos familiares à comunicação com os professores

\begin{tabular}{cc}
\hline NOTA & N \\
\hline 5 & 1 \\
7 & 1 \\
8 & 1 \\
10 & 2 \\
\hline & MÉDIA $=8$ \\
\end{tabular}

Fonte: Elaborado pelas autoras (2020).

Constata-se que a nota média atribuída à comunicação entre familiares e professores durante o isolamento é relativamente boa, atingindo a média oito, embora haja uma nota consideravelmente baixa (nota 5).

Apesar desta média, ao questionadas sobre a necessidade de melhoria da relação entre familiares e professores durante o período, $60 \%(\mathrm{~N}=3)$ das mães 
responderam positivamente, ou seja, julgavam que o relacionamento e a comunicação entre ambos deveriam ser mais próximos e frequentes. Do total de mães, 40\% ( $\mathrm{N=2}$ ) declarou não ser necessário haver modificações nesta relação.

Neste cenário, é essencial que a relação entre professores e família esteja cada vez mais próxima, uma vez que os familiares estão ainda mais envolvidos e responsabilizados pelas atividades escolares da criança. Deste modo, o envolvimento e a parceria entre ambos, que consiste em uma prática importante e que beneficia a trajetória escolar do aluno (CHRISTOVAM; CIA, 2016; SILVA; CABRAL; MARTINS, 2016), torna-se essencial em um contexto em que os pais têm um papel e uma função tão diretos e relevantes neste processo.

Essa necessidade de aproximação se reafirma, dentre outros fatores, no fato de que grande parte dos pais/responsáveis não possuir formação ou habilidades pedagógicas e didáticas para conduzir e instruir os filhos nestas atividades. Não obstante, sabe-se que em muitos contextos existem, inclusive, familiares com graus de escolaridade inferior aos dos filhos, e estas características precisam ser consideradas pela equipe escolar e fazer parte do conjunto de orientações e informações a ser passado à família. Assim, por meio do diálogo e contato frequente, cria-se um vínculo e uma parceria para que a família possa recorrer ao professor para tirar dúvida ou receber instruções sobre as atividades escolares a serem realizadas com a criança.

A Figura 2 apresenta as ferramentas utilizadas para os contatos entre professores e as mães.

\section{Figura 1. Ferramentas utilizadas na comunicação entre família e escola}

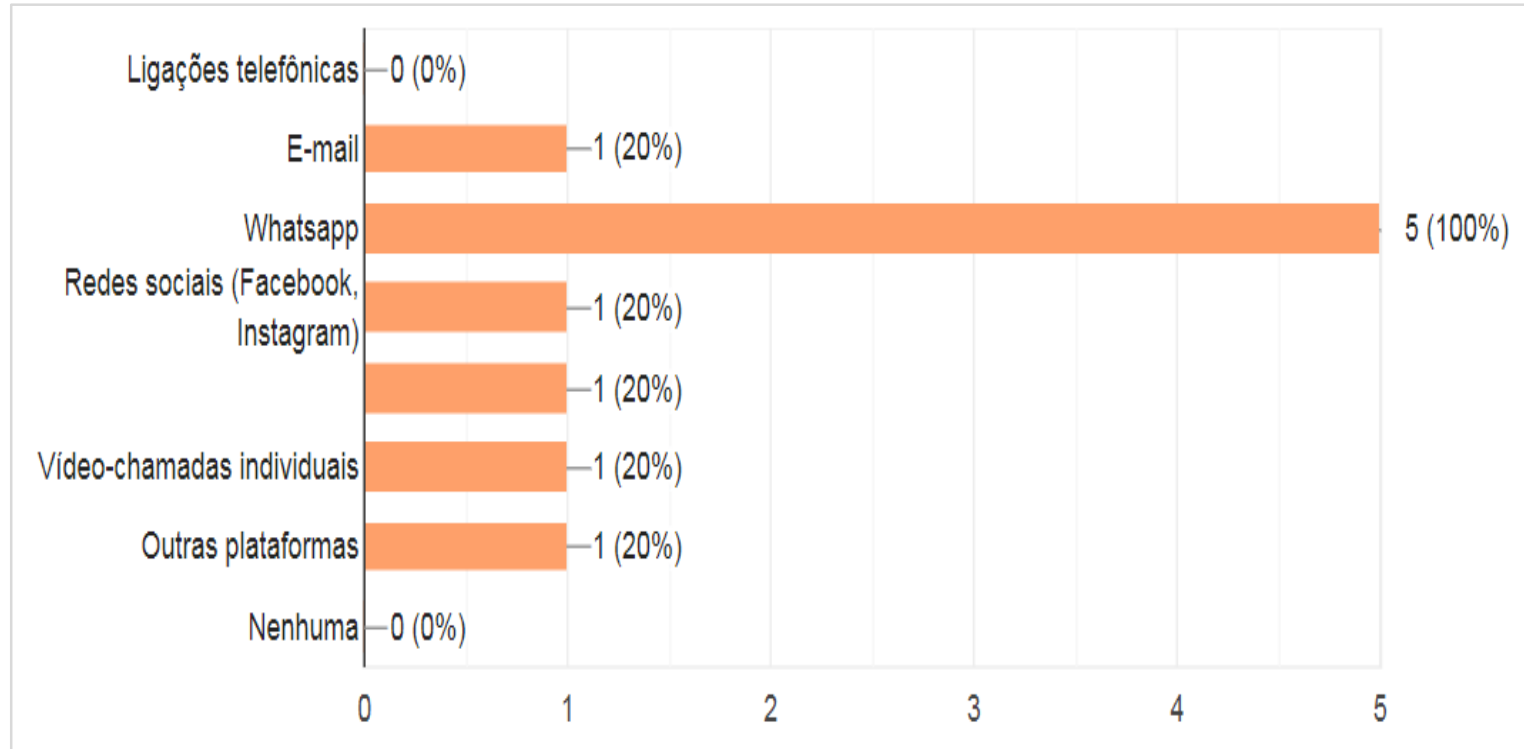

Fonte: Elaborado pelas autoras (2020).

A partir da Figura 2 constata-se que a ferramenta mais utilizada para o estabelecimento de diálogos entre os contextos foi o aplicativo de mensagens WhatsApp, mencionada por todas as participantes. Contudo, é possível perceber uma pouca variedade nos recursos de comunicação utilizados, pois os demais tiveram uma frequência baixa $(\mathrm{N}=1)$. 
Tal dado pode se referir à praticidade, agilidade e variedade de funções e recursos que este aplicativo oferece aos usuários, sendo é possível enviar mensagens de texto escrita, mensagens de áudio gravado, vídeos gravados, arquivos, fotos e, inclusive, realizar vídeo chamadas ao vivo. Além disso, sua utilização em um smartphone é suficiente, não sendo necessário que a família disponha de um computador ou notebook.

Pode-se confirmar a satisfação das mães com o uso deste recurso a partir da constatação de que, quando perguntadas sobre a eficácia da ferramenta de comunicação, $100 \%$ das mães responderam positivamente.

Quando questionadas sobre terem recebido instruções de como planejar a rotina e auxiliar a criança em casa nas atividades escolares, $60 \%$ das participantes declararam ter recebido $(\mathrm{N}=3), 20 \%$ declarou ter recebido de forma insuficiente $(\mathrm{N}=1)$, e $20 \%$ informou não ter recebido instrução $(\mathrm{N}=1)$.

Neste ponto, retoma-se a discussão anterior sobre a necessidade de que os familiares que estão lidando diretamente com as atividades escolares da criança, no acompanhamento e condução das atividades, recebam as informações e orientações necessárias, pois a maioria destes não está preparada e capacitada para este papel - que lhe fora repentinamente imposto e tem sido constantemente cobrado.

Em relação à existência de algum obstáculo para que haja uma comunicação mais eficiente entre família e escola, as mães indicaram: disponibilidade $(\mathrm{N}=1)$; e serviço de internet $(\mathrm{N}=1)$. As demais declararam não haver obstáculo.

Estas informações reforçam as particularidades de cada contexto, pois, famílias diferentes possuem experiências e necessidades diferentes, e o que pode ser uma barreira ou dificultador para determinado núcleo familiar, pode não ser para outro.

Por este motivo, a equipe escolar precisa estar atenta e sensível às particularidades dos contextos familiares de seus alunos (SAISI, 2010; BORGES, 2018), identificando essas barreiras e auxiliando-os a superá-las, para que estes possam, por fim, realizar as atividades escolares junto à criança com o mínimo de intercorrência possível.

Ao serem indagadas sobre sugestões para aprimorar a relação, foram mencionadas: vídeo chamadas, vídeo aulas e aulas particulares. Três mães não apontaram sugestões por estarem satisfeitas com o relacionamento.

Tais sugestões refletem uma possível percepção das mães de que um contato visual e/ou ao em tempo real entre a criança e o professor favorece e maximiza o processo de ensino e atividades escolares no formato remoto.

A relação das mães com as demandas durante o isolamento é apresentada na Figura 3.

\subsection{Relação das famílias com as demandas da rotina durante isolamento social}

As participantes também responderam questões que abordavam sobre o dia a dia em casa e a forma com que estavam lidando com demandas do cotidiano. A Figura 3 mostra a relação das famílias com as demandas da rotina. 


\section{Figura 2. Relação do familiar com demandas da rotina}

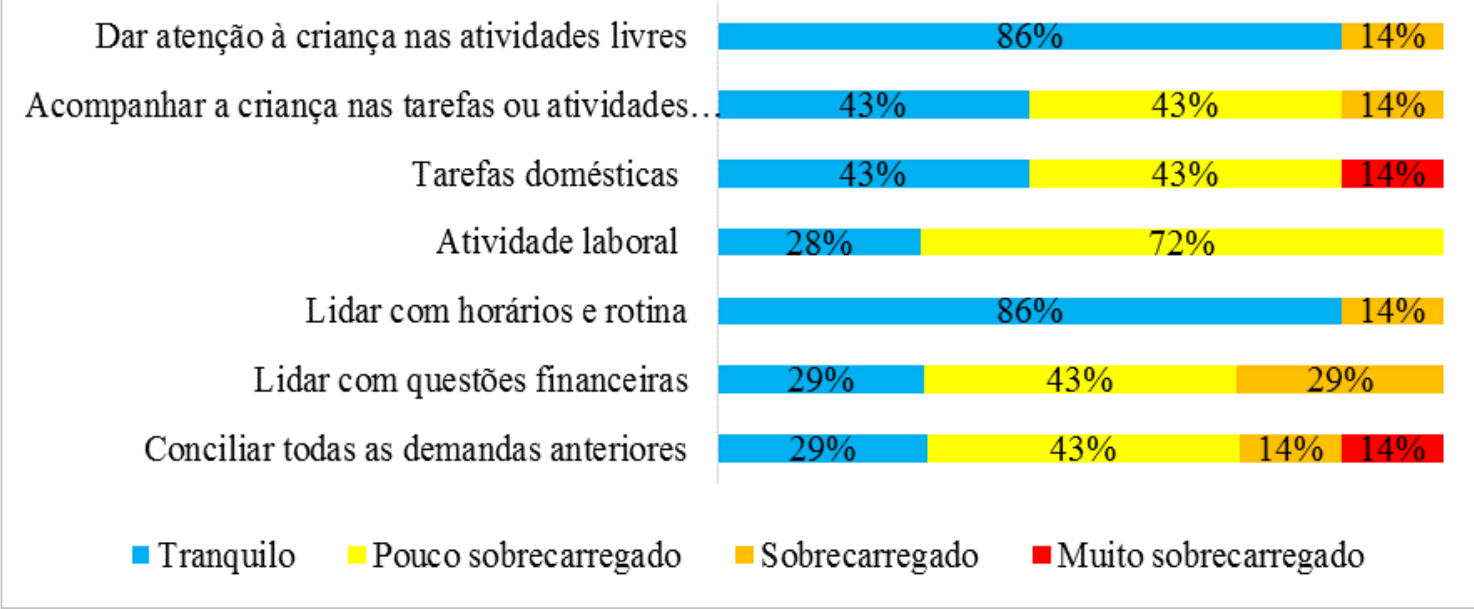

Fonte: Elaborado pelas autoras (2020).

Os dados demonstram que as atividades diárias que a mães têm mais facilidade em administrar são "atenção à criança nas atividades livres" e "lidar com horários e rotinas". Em contraponto, as que geram mais sobrecarga são "tarefas domésticas" e o "conciliar todas as demandas anteriores".

Estes dados refletem a sobrecarga já comumente depositada sobre as mães (ALEXANDRE, 2012; GUALDA; BORGES; CIA, 2013; SILVA; KAULFUSS, 2015; BOTELHO, 2016). Estas, além de desenvolverem suas atividades profissionais, muitas vezes, precisam realizar todas as atividades domésticas da casa, organizar a rotina e horários da família e zelar pelos assuntos escolares e cuidados para com as crianças.

Considerando este cenário de reorganização diante da pandemia, soma-se a todas essas, a necessidade de gerenciar seus dias de forma a terem tempo para acompanharem as atividades escolares das crianças no formato remoto. Sem dúvidas, este período tem gerado aumento na carga de trabalho e nas funções destas mães, que ainda tentam reservar períodos de lazer, descontração e brincadeiras com os filhos, muitas vezes, abrindo mão de qualquer possibilidade de descanso, como já discutiram Bertolini (2002) e Paniagua (2004).

Estes fatores, por sua vez, sofrem influência de inúmeras variáveis, como: suporte e ajuda de outras pessoas que residem na mesma casa; rede de apoio, como parentes, vizinhos e amigos; situação econômica; modalidade e carga horária de trabalho; dentre outros.

Por este motivo, é preciso que os profissionais escolares estejam sempre alertas e sensíveis às especificidades que as famílias apresentam, evitando realizar cobranças e solicitações que vão além das capacidades de cada ambiente familiar e, como visto, das mães, aumentando a sobrecarga.

A Figura 4 mostra a frequência com que as participantes realizavam determinadas atividades com a criança. 


\section{Figura 3. Frequência de realização de atividades com a criança}

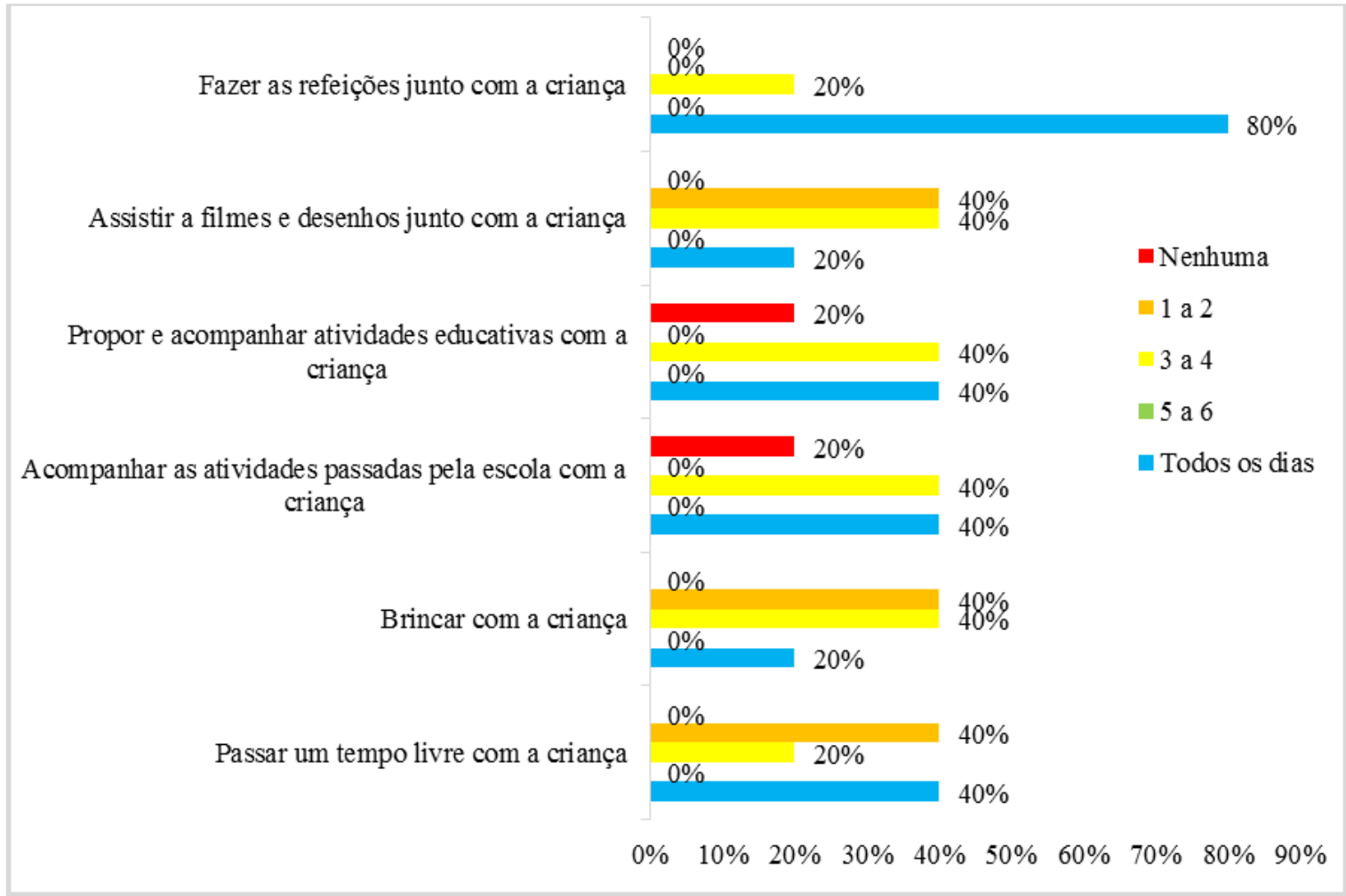

Fonte: Elaborado pelas autoras (2020).

Constata-se que, em suas rotinas, a atividade que as mães conseguem fazer com mais frequência junto à criança são as refeições. Na sequência, têm a categoria "passar tempo livre com a criança", como a mais frequentemente realizada.

Entretanto, ações como "propor e acompanhar atividades educativas" (jogos, leituras, desenhos, etc.) e "acompanhar as atividades propostas pela escola" foram as que tiveram menor frequência. Embora $40 \%$ tenha declarado fazê-las todos os dias, $20 \%$ declarou nunca conseguir fazer, e $20 \%$ declarou fazer entre 3 e 4 vezes na semana.

Já atividades mais livres e menos direcionadas, como brincar e assistir a filmes e desenhos, tiveram uma frequência mediana, semelhante aos achados de Gualda, Borges e Cia (2013), analisando o contexto familiar de crianças com deficiência.

Os dados apresentados permitem identificar que o envolvimento das mães nas atividades escolares está com uma frequência inferior, o que pode indicar que as mães não estão conseguindo acompanhar estas atividades, apesar de esta ação não ter sido apontada como a que gera maior sobrecarga (Figura 3 ).

Contudo, não se sabe a causa desta frequência. Talvez haja um outro familiar envolvido nesta atividade (como um pai ou irmão mais velho), ou a criança esteja participante das aulas e atividades remotas sem acompanhamento. Outra possibilidade é que a criança não esteja sendo assídua às atividades acadêmicas, o que seria ainda mais preocupante. 


\section{Considerações finais}

A partir dos resultados apresentados é possível fazer algumas considerações a respeito da rotina familiar e acadêmica durante o isolamento social.

Primeiramente, se destaca o fato de $100 \%$ dos participantes serem mães, o que já é uma tendência, ressaltando que a função de responsável, cuidadora e administradora do ambiente familiar, dos filhos e de suas atividades acadêmicas ainda recai sobre a mulher.

Verifica-se também que, na amostra analisada, o contato com os professores tem sido satisfatório, ainda que tenham indicado a necessidade de melhoria. Embora a maior parte das mães tenha recebido instruções de forma suficiente sobre como proceder em relação às atividades acadêmicas, este é um fator que necessita urgentemente de atenção, pois significa que $40 \%$ não as recebeu, ou recebeu de forma insuficiente.

Esta questão é preocupante, pois pode ameaçar o rendimento acadêmico da criança e até mesmo sua evolução, visto que se trata de crianças entre três e seis anos -um período muito crítico e crucial de desenvolvimento.

Embora a maioria tenha recebido instruções sobre o ensino, é preocupante constatar que $40 \%$ não recebeu ou recebeu insuficientemente. Tal fato torna-se inquietante ao considerar sua implicação no rendimento acadêmico e evolução dos alunos, visto que estão em um período desenvolvimental crucial; além de aumentar a desigualdade de acesso e qualidade da educação e, consequentemente, a desigualdade social. Não obstante, esse fator por vir a aumentar ainda mais a desigualdade de acesso à educação e formação dos alunos no país e, consequentemente, a desigualdade social.

Também se destaca o papel dos recursos tecnológicos, principalmente dos aplicativos de smartphone, para no auxílio do suprimento da demanda do contato entre a família e escola.

Contudo, a sobrecarga materna, sua dificuldade em compartilhar das atividades da criança, a insuficiência das orientações escolares, a necessidade de aprimoramento da comunicação e a não-variedade das ferramentas utilizadas para tal, são passíveis de intervenção, devendo ser foco de ação dos governantes, diretores e professores.

Crê-se que essa investigação possibilitará mapear as características singulares de cada contexto, assim como os impactos da modalidade de ensino no ambiente familiar, e da família no processo de ensino. Desta maneira, torna-se possível acompanhar mais proximamente este processo, de modo a entender seu funcionamento e registrar seu movimento, uma vez que se trata de um fato excepcional, assim como, identificar possíveis pontos de ação, de forma a intervir e otimizar este percurso.

\section{REFERÊNCIAS}

ALEXANDRE, Susana. Estratégias para promover a aproximação famíliaescola. Beja, Portugal. 2012. Disponível em:

http://comum.rcaap.pt/handle/123456789/3982. Acesso em: 24 abr. 2020. 
BERTOLINI, Luciana Benatti de Almeida. Funções paternas, maternas e conjugais na Sociedade Ocidental. In: BERTOLINI, Luciana Benatti de Almeida (Org.).

Relações entre o trabalho da mulher e a dinâmica familiar. São Paulo: Vetor, p. 27-31, 2002.

BORGES, Laura. Relação família e escola: programa para profissionais préescolares de alunos público alvo da educação especial. 2015. Dissertação (Mestrado). Programa de Pós-Graduação em Educação Especial, Universidade Federal de São Carlos, São Carlos, 2015. 201 f.

BORGES, Laura. Família-escola: curso de formação para professores préescolares de alunos do público-alvo da educação especial. Tese (Doutorado). Programa de Pós-Graduação em Educação Especial, Universidade Federal de São Carlos, São Carlos, 2018. 255 f.

BORGES, Laura; GUALDA, Danielli Silva; CIA, Fabiana. Relação família e escola e Educação Especial: opinião de professores. Educação: Teoria e Prática, v. 25, n. 48 , p. $168-185,2015$.

BOTELHO, Francisca Rogério Silva. A participação da família na escola. Revista Eventos Pedagógicos, Sinop, v.7, n. 2, p. 426-440, 2016.

BRASIL. Cartilha Novas Orientações: Coronavírus, Covid -19. Ministério da Saúde, 2020. Disponível em:

https://www.saude.gov.br/images/pdf/2020/April/07/Cartilha-CoronavirusInformacoes-.pdf. Acesso em: 01 jun. 2020.

CHRISTOVAM; Ana Carolina Camargo; CIA, Fabiana. Comportamentos de pais e professores para a promoção da relação família e escola de pré-escolares incluídos. Revista Educação Especial, Santa Maria, v. 29, n. 54, p. 133-146, 2016.

CONSELHO REGIONAL DE FARMÁCIA DO ESTADO DE SÃO PAULO. Informe técnico sobre novo Coronavírus (2019-nCoV). 2020. Disponível em:

http://www.crfsp.org.br/images/arquivos/coronavrus_infome_tecnico.pdf. Acesso em 01 jun. 2020.

COZBY, Paul. Métodos de pesquisa em ciências do comportamento. ed. 2. São Paulo: Editora Atlas, p. 454. 2006.

DESSEN, Maria Auxiliadora; SILVA, Nara Liana Pereira. Deficiência mental e família: implicações para o desenvolvimento da criança. Psicologia: teoria e pesquisa, Brasília, v. 17, n. 2, p. 133-141, 2001.

GIL, Antônio Carlos. Métodos e técnicas de pesquisa social. 5. ed. São Paulo: Atlas, 1999.

GOITEIN, Paula Cruz; CIA, Fabiana. Interações familiares de crianças com necessidades educacionais especiais: revisão da literatura nacional. Revista 
Semestral da Associação de Psicologia Escolar e Educacional, Campinas, v. 15 , n. 1 , p. 43-51, 2011.

GUALDA, Danielli Silva; BORGES, Laura; CIA, Fabiana. Famílias de crianças com necessidades educacionais especiais: recursos e necessidades de apoio. Revista Educação Especial, Santa Maria, v. 26, n. 46, p. 307-330, 2013.

LOPES, Claudia Cristina Garcia Piffer. Trabalho com as famílias na educação infantil: concepções e práticas. 2008. f. 136. Dissertação de Mestrado, Programa de Pós-graduação em Educação, Faculdade de Ciências e Tecnologias - UNESP, Presidente Prudente, 2008.

OLIVEIRA, Maria do Céu Gomes Leal. Relação família-escola e participação dos pais. Dissertação de Mestrado em Educação, Instituto Superior de Educação e Trabalho, Porto, 2010.

OLIVEIRA, Cynthia Bisinoto Evangelista; MARINHO-ARAÚJO, Claisy Maria. A relação família-escola: interseç̧ões e desafios. Estudos de Psicologia, Campinas, v. 27, n. 1, p. 99-108, 2010.

ORGANIZAÇÃO MUNDAL DA SAÚDE. Folha informativa COVID-19 - Escritório da OPAS e da OMS no Brasil. Disponível em: https://www.paho.org/pt/covid19. Acesso em: 01 jun. 2020.

PANIAGUA, Gema. As famílias de crianças com necessidades educativas especiais. In: COLL, César.; MARCHESI, ALVARO; PALACIOS, JESúS. (Orgs.).

Desenvolvimento Psicológico e Educação: transtornos de desenvolvimento e necessidades educativas especiais. Porto Alegre: Artmed, 2004, p. 330-346.

REIS, Janete dos Santos. Relação família e escola: a experiência em uma escola pública de periferia de Salvador-BA. 2013. Dissertação (Mestrado). Programa de Pós-Graduação em Família na Sociedade Contemporânea, Universidade Católica do Salvador, 2013. $128 \mathrm{f}$.

RIBEIRO, Joana Maria de Magalhães. A colaboração entre a família de crianças com necessidades educativas especiais e a escola: percepções de pais e educadores de infância/professor do $1^{0}$ ciclo. Lisboa, Portugal. 2012.

Disponível em: https://core.ac.uk/download/pdf/62687994.pdf. Acesso em: 24 abr. 2020.

SAISI, Neide Barbosa. Educação infantil e família: uma parceria necessária.

Educação: Teoria e prática, Rio Claro, v. 20, n. 4, p. 65-85, 2010.

SÃO PAULO, GOVERNO DO ESTADO. Orientações Coronavírus. Secretaria de Educação, 2020a. Disponível em: https://www.educacao.sp.gov.br/wpcontent/uploads/2020/03/Coronavirus-Orientac\%CC\%A70\%CC\%83esba\%CC\%81sicas.pdf.pdf-1.pdf.. Acesso em 01 jun. 2020. 
SÃO PAULO, GOVERNO DO ESTADO. Documento orientador - Atividades a distância e de conscientização sobre a prevenção ao Coronavírus. Comunicado COPED, 2020b. Disponível em:

http://www.escoladeformacao.sp.gov.br/portais/Portals/84/docs/pdf/Documento\% 20orientador\%20-

\%20Atividades $\% 20$ a\%20dista\%CC\%82ncia\%20e\%20de\%20conscientizac\%CC\%A7 a\%CC\%830\%20sobre\%20a\%20prevenc\%CC\%A7a\%CC\%830\%20ao\%20coronavi $\%$ CC\%81rus.pdf. Acesso em: 01 jun. 2020.

SÃO PAULO, GOVERNO DO ESTADO. Decreto no $\mathbf{6 4 . 8 8 1}$, de 22 de março de 2020c. Decreta quarentena no Estado de São Paulo, no contexto da pandemia do COVID-19 (Novo Coronavírus), e dá providências complementares. Disponível em: https://www.saopaulo.sp.gov.br/wp-content/uploads/2020/03/decretoquarentena.pdf. Acesso em: 01 jun. 2020.

SILVA, Catia Regina; KAULFUSS, Marco Aurélio. A importância da família na educação infantil. Revista científica eletrônica de ciências aplicas da FAIT. Disponível em: http://fait.revista.inf.br/site/c/pedagogia.html. Acesso em: 03 abr. 2020.

SILVA, Aline Maira; CABRAL, Leonardo Santos Amâncio; MARTINS, Morgana de Fátima Agostini. Abordagem relacional entre família e escola inclusiva sob as perspectivas de professores. Interfaces da educação, Paranaíba, v. 7, n. 19, p. 191-205, 2016.

SOCIEDADE BRASILEIRA DE INFECTOLOGIA. Informe da Sociedade Brasileira de Infectologia (sbi) sobre o novo coronavírus. Associação Médica Brasileira, 2020. Disponível em: https://infectologia.org.br/wpcontent/uploads/2020/07/informe-13-medicacoes-para-covid-19.pdf. Acesso em: 01 jun. 2020.

Recebido em: 20 de julho de 2020. Aceito em: 28 de outubro de 2020. Publicado em: 05 de janeiro de 2021. 